\title{
Milk runs model with overtime: application to cluster supply chain
}

\author{
Michał Tomczak, Robert Bucoń
}

\section{Department of Construction Project Engineering, Faculty of Civil Engineering and Architecture, Lublin University of Technology,e-mail: m.tomczak@pollub.pl,r.bucon@pollub.pl}

\begin{abstract}
Paper identifies obstacles limiting functioning and development of small and medium construction enterprises. It also includes a description of cluster supply chain (CSC) idea as a suggested solution to some of the problems resulting from the small scale of company activities. One of more important issues of every distribution centre, i.e. portions of deliveries smaller than truck capacity for particular consumers, is also discussed. This problem was formulated for the first time in dairy industry, therefore, it was called milk runs. Moreover, the authors of this paper presented the outcome analysis of survey carried out among construction engineers and managers. This study aimed at determining organizational principles for logistic centre working with CSC framework. The mathematical model depicting milk runs deliveries with overtime consideration, done for many construction sites within a distribution centre is presented hereunder. This model may be potentially used to optimize distribution centres working within cluster supply chain framework.
\end{abstract}

Keywords: cluster supply chain, mathematical programming, multi-objective optimization, small and medium enterprises

\section{Introduction}

The task of logistics - understood as the process of supply chain management - is the optimization of physical flows of resources and information, with regard to the source of materials and suppliers, the policy of purchase and raw material collection, material flow within the organization, storage of finished products, distribution channels, ways to store and modes of transport [1,2]. It affects the efficiency of every sphere of construction enterprise operations, its policy as a whole, therefore, it is frequently a key component of organization functioning, which determines its competitiveness on the increasingly demanding market [3].

The purpose of the article is to identify and depict the barriers limiting the operation and development of small and medium construction enterprises. Moreover, the concept of cluster supply chain is also presented as a suggested solution to the part of the problems resulting from the small scale of operating activity. In addition, the survey results were analyzed, which was conducted among engineers and managers related to the construction sector in order to determine the operating principles of distribution center functioning as part of cluster supply chain. 


\section{Barriers in the implementation of the integrated supply chain in the case of small and medium construction enterprises}

Total integration of supply chain consists in internal and external consolidation. Enterprises from every link of a chain cooperate closely to satisfy the customers' needs in the best way [4 -7]. The cooperation covers both financial, physical and information flows. Nevertheless, the implementation of integrated supply chain is particularly difficult in the case of small and medium construction companies $[3,5,6]$. The following barriers are mentioned in the literature while implementing the integrated supply chain $[2,3,6-11]$ :

- strategy short-sightedness,

- lack of confidence between enterprises,

- attachment to standard quality management tools,

- insufficient or lack of knowledge of the rules in force in the supply chain management,

- high costs of implementation,

- lack of time,

- the need for outside support.

However, the key problem of small and medium construction enterprises is not the occurrence of one particular limitation, but the accumulation of multiple separate barriers $[3,6,12]$.

\section{The concept of cluster supply chain}

The answer to the problem of small and medium enterprises in implementing modern logistics solution can be the implementation of a cluster supply chain idea (CSC). CSC is a new concept of logistics management which was created as a result of combination of two ideas: industry cluster and supply chain management $[3,6,13]$.

The cluster supply chain is a network composed of horizontal and vertical links between companies $[3,6,13]$. As a result of horizontal links (with different companies dealing with the same link of supply chain), enterprises can together achieve the operating scale exceeding their individual possibilities e.g. collective purchase at lower unit price, the achievement of optimal scale of equipment operation, enabling the realization of large orders, and even competing with huge construction companies [3, 6, 13]. Meanwhile, by the vertical links (with companies dealing with different links in a supply chain) they can reduce level of stocks, improve the timeliness of deliveries and adjust their number to the current needs, or reduce the uncertainty of the made decisions. The combination of industry cluster and supply chain management, operating as a regional, effective and economic cooperation platform, allows small and medium companies to survive, develop and improve their competitiveness $[3,6,13]$.

The key benefits of cluster supply chain implementation are [3, 6, 14]:

- improvement of competitiveness,

- achievement of cost-effective scale of operations,

- better bargaining and competitive position,

- improvement of economic environment, e.g. by creating the groups of highly qualified workers,

- benefits from the exchange of knowledge, experience, information. 


\section{Determining criteria weights}

Due to its simplicity, easy implementation and intuitiveness in modeling the preferences of decision-maker, one of the most widely used, optimal multi-criteria methods in engineering applications is Weighted Global Criterion Method (WGCM) [4]. In the case of this method, all the criteria are reduced to the only one function of usability, and the weights vector is additive.

The most problematic task while using WGCM is the precise determination of criteria weights [15]. In order to solve this problem, the fuzzy approach is applied e.g. proposed by Tzeng and Huang in Fuzzy Simple Additive Weighting Method (FSAW) [16]. This method makes use of triangular fuzzy numbers to model decision-maker's preferences. The original procedure FSAW refers to the support while making a decision, and hence it takes into account the imprecision in experts' evaluations, yet in the further part of the article, a modified approach to determine criteria weights, based on the procedure FSAW, will be presented and used.

The algorithm of the method is as follows [15]:

Step 1. For $u=1,2, \ldots, s$ criteria, the fuzzy weights $v_{u}$ are determined in the form of triangular fuzzy numbers $\left(a_{u}, m_{u}, c_{u}\right)$ by the dialogue with a decision-maker:

- by the answer to the question "What is the minimal value of weight?", the $a_{u}$, parameter is obtained,

- by the answer to the question 'What is the most appropriate value of weight?', the $\mathrm{m}_{u}$, parameter is obtained,

- by the answer to the question 'What is the maximal value of weight?, the $\mathrm{c}_{u}$, parameter is obtained.

It was assumed that:

$$
\sum_{u=1}^{s} m_{u}=1
$$

Step 2. Standardized evaluations of variant $K_{u}$ in reference to $u$ criterion (assuming that the usability function is maximized) are determined:

- for the profitable criteria (the more the better):

$$
K_{u}(\mathbf{x})=\frac{R_{u}(\mathbf{x})-R_{u}^{\min }}{R_{u}^{\max }-R_{u}^{\min }}, \quad \forall u=1,2, \ldots, s,
$$

where: $\mathbf{x}$ - vector of decision variables, $R_{u}(\mathbf{x})$ - the obtained evaluation of variant in reference to $u$ criterion, $R_{u}^{\min }$ - the minimal possible to achieve evaluation of variant in reference to $u$ criterion, $R_{u}^{\max }$ - the maximal possible to achieve evaluation of variant in reference to $u$ criterion,

- for the cost criteria (the less the better):

$$
K_{u}(\mathbf{x})=\frac{R_{u}^{\min }-R_{u}(\mathbf{x})}{R_{u}^{\min }-R_{u}^{\max }}, \quad \forall u=1,2, \ldots, s .
$$

Step 3. Defuzzified value of weight $v_{u}$ is calculated (by Center of Gravity Method): 
$v_{u}=\frac{a_{u}+m_{u}+c_{u}}{3}, \quad \forall u=1,2, \ldots, s$.

Step 4. The assessments are calculated:

$$
K_{u}=\sum_{u=1}^{s} v_{u} K_{u}(\mathbf{x})
$$

The maximization of evaluation value provides the selection of optimal solution.

\section{The mathematical model of milk runs problem with regard to optional constructions}

One of the most significant problems of every distribution center is the material delivery by instalments - for particular customers - lower than the car capacity. This issue has been formulated for the first time in order to plan the transport in milk industry - for this reason such a problem is frequently known as milk runs [17]. In reference to construction, the issue of milk runs most frequently occur in distributing expensive finishing materials which are used in relatively small quantities. The mathematical model, depicting supplies with the 'milk run' principle implemented as part of distribution center serving many building sites [3], is shown below. For some of construction sites, deliveries must be effected on the day in question (mandatory constructions), however, supplies to other building sites have extra time and can be carried out on the day in question, or during subsequent days (optional constructions). In order to determine the profitability of the performed delivery during the considered day, two contradictory criteria were examined: timeliness of supply and the labour costs of drivers (taking into account a higher rate for overtime work). The function of the purpose of a model considers fuzzy weights criteria obtained by the Fuzzy Simple Additive Weighting Method. The constraints are: working time of drivers, demand of customers and car capacity.

The following parameters were introduced to the mathematical description of a model:

$M$ - a single-piece set representing distribution center, $M=\{0\}$,

$W$ - the set of mandatory constructions, $W=\{1,2, \ldots, w\}$,

$O$ - the set of optional constructions, $O=\{w+1, w+2, \ldots, n\}$,

$P$ - the set of all points, $P=M \cup W \cup O, P=\{0,1,2, \ldots, n\}$,

$D$ - the set of vehicles, $D=\{1,2, \ldots, m\}$,

$b_{j}$ - the demand of point $j[\mathrm{j} . \mathrm{m}],. b_{0}=0$,

$\ell_{k}-$ load capacity of a car $k$,

$T_{k}$ - standard fund of operating time of a car driver $k$,

$T_{k}$ - maximal working time of a car driver $k$,

$t_{i j}$ - the travel time between points $i$ and $j$,

$C-$ a driver's hourly rate working within the framework of operating time fund,

$c-$ a driver's overtime bonus,

$K_{1}-$ standardized costs of drivers' labour, 
$K_{2}-$ standardized value of timeliness of supplies,

$v_{1}$ - fuzzy weight of drivers' labour costs,

$v_{2}$ - fuzzy weight of timeliness of supplies,

$R_{l}$ - drivers' labour costs,

$R_{1}^{\min }-$ minimal, possible to achieve value of labour costs of drivers,

$R_{1}^{\max }$ - maximal, possible to achieve value of labour costs of drivers,

$R_{2}-$ timeliness of supplies,

and the variables:

$x_{i j k}=\left\{\begin{array}{l}1, \text { when vehicle } k \text { travels from point } i \text { to point } j, \\ 0, \text { in the opposite case, }\end{array}\right.$

$y_{i j k}=\left\{\begin{array}{l}1, \text { when vehicle } k \text { travels from point } i \text { to point } j \text { within the framework } \\ \text { of labour fund, } \\ 0, \text { in the opposite case. }\end{array}\right.$

The following conditions must be fulfilled for the problem to have the final solution:

$$
\begin{aligned}
& \max _{j \in W \cup O} b_{j} \leq \max _{k \in D} E_{k}, \\
& \sum_{j=1}^{n} b_{j} \leq \sum_{k=1}^{m} Ł_{k} .
\end{aligned}
$$

The function of the objective (maximization of the variants utility):

$\max z: z=v_{1} K_{1}+v_{2} K_{2}$,

Under restrictive conditions:

$$
\begin{aligned}
& R_{1}=\sum_{i=0}^{n} \sum_{j=0}^{n} \sum_{k=1}^{m} y_{i j k} \cdot t_{i j} \cdot C+\sum_{k=1}^{m}\left(\sum_{i=0}^{n} \sum_{j=0}^{n} x_{i j k} \cdot t_{i j}-\sum_{i=0}^{n} \sum_{j=0}^{n} y_{i j k} \cdot t_{i j}\right) \cdot c, \\
& K_{1}=\frac{R_{1}^{\min }-R_{1}}{R_{1}^{\min }-R_{1}^{\max }}, \\
& R_{2}=\sum_{i=0}^{n} \sum_{k=1}^{m} x_{i j k}, \quad \forall j=w+1, w+2, \ldots, n, \\
& K_{2}=\frac{R_{2}-(w+1)}{n-(w+1)}, \\
& \sum_{i=0}^{n} \sum_{k=1}^{m} x_{i j k}=1, \quad \forall j=1,2, \ldots, w,
\end{aligned}
$$




$$
\begin{aligned}
& \sum_{j=0}^{n} \sum_{k=1}^{m} x_{i j k}=1, \quad \forall i=1,2, \ldots, w, \\
& \sum_{i=0}^{n} \sum_{k=1}^{m} x_{i j k} \leq 1, \quad \forall j=w+1, w+2, \ldots, n,
\end{aligned}
$$

$\sum_{j=0}^{n} \sum_{k=1}^{m} x_{i j k} \leq 1, \quad \forall i=w+1, w+2, \ldots, n$,

$\sum_{i=0}^{n} \sum_{k=1}^{m} x_{i j k}=\sum_{j=0}^{n} \sum_{k=1}^{m} x_{j i k}, \quad \forall j=w+1, w+2, \ldots, n$,

$\sum_{i=0}^{n} x_{i 0 k}=\sum_{j=0}^{n} x_{0 j k}=1, \quad \forall k=1,2, \ldots, m$,

$x_{i j k}+x_{j i k} \leq 1, \quad \forall i=1,2, \ldots, n, \quad \forall j=1,2, \ldots, n, \quad \forall k=1,2, \ldots, m$,

$x_{i j k} \geq y_{i j k} \quad \forall i=0,1,2, \ldots, n, \quad \forall j=0,1,2, \ldots, n, \quad \forall k=1,2, \ldots, m$,

$\sum_{i=0}^{n} \sum_{j=0}^{n} x_{i j k} t_{i j} \leq t_{k}, \quad \forall k=1,2, \ldots, m$,

$\sum_{i=0}^{n} \sum_{j=0}^{n} y_{i j k} t_{i j} \leq T_{k}, \quad \forall k=1,2, \ldots, m$,

$\sum_{k=1}^{m} x_{i j k} \leq 1, \quad \forall i=0,1,2, \ldots, n, \quad \forall j=0,1,2, \ldots, n$,

$\sum_{i=0}^{n} \sum_{j=0}^{n} x_{i j k} b_{j} \leq t_{k}, \quad \forall k=1,2, \ldots, m$

$\sum_{i=0}^{n} x_{i j k}=\sum_{i=0}^{n} x_{j i k}, \quad \forall j=1,2, \ldots, n, \quad \forall k=1,2, \ldots, m$,

$x_{i j k} \in\{0,1\}, \quad \forall i=1,2, \ldots, n, \quad \forall j=1,2, \ldots, n, \quad \forall k=1,2, \ldots, m$,

$y_{i j k} \in\{0,1\}, \quad \forall i=1,2, \ldots, n, \quad \forall j=1,2, \ldots, n, \quad \forall k=1,2, \ldots, m$.

Equation (9) defines the labour cost of drivers with regard to higher rates for overtime hours worked. The condition (10) describes standardized labour costs of drivers. The equation (11) defines the timeliness of supplies, and (12) standardized value of this 
parameter. The condition (13) ensures that only one single car will arrive in every mandatory city. The equation (14) ensures that only one single car will leave every mandatory city. The restriction (15) ensures that no more than one car will arrive in every optional city. The restriction (16) ensures that no more than one car will leave every optional city (it is optional restriction arising out of the others). The restriction (17) ensures that the number of cars which arrives in the optional city will be equal to the number of cars which leaves the city. The requirement (18) ensures that the number of cars which leaves the distribution center is equal to the number of cars which arrives in the center, namely, the number of cars. The equation (19) prevents the creation of several separate routes (loops) for one car. The restriction (20) ensures that the supplies carried out within the framework of the fund of drivers' operating time will be included in the deliveries made throughout the day in question. The inequality (21) ensures that drivers' operating time will not be exceeded, which in turn defines the condition (22). The condition (23) ensures the carriage of materials on one route by no more than one car. The restriction (24) ensures that the car capacity will not be exceeded. The restriction (25) ensures that the same car will arrive in and leave a given city. The restrictions (26) and (27) guarantee binary variables $x_{i j k}$ and $y_{i j k}$.

\section{Example}

The distribution center has two light commercial vehicles: a car A with the capacity $P$, and a car B which has the capacity of $20 \%$ bigger than the first vehicle $-120 \% \mathrm{P}$. The maximum driver's operating time of a car A is 12 hours daily, and the driver of a car B - 10 hours daily, whereas for every overtime hour worked, the driver collects a rate higher by $20 \%$ than the one within the framework of labour fund which is 10 hours daily for the driver of a car A and 8 hours for the driver of a car B. The demand of construction sites for the material is shown in Table 1, whereas the constructions I, II and III must be supplied on the day in question, however, the constructions IV and V have the possibility of accumulating material supply and can be served on the day in question or on the next day. Travel time between particular construction sites and a distribution center (marked as 0 ) is presented in Table 2.

The best route should be selected due to the criteria of costs and supply timeliness with regard to the results of a survey conducted among construction managers and engineers in accordance with the rules demonstrated in the algorithm of FSAW Method (shown in Table 3).

Table 1. The demand of construction sites expressed as a percentage of car A capacity

\begin{tabular}{cccccc}
\hline Construction & I & II & III & IV & V \\
\hline Demand & $60 \%$ & $30 \%$ & $40 \%$ & $50 \%$ & $20 \%$ \\
\hline
\end{tabular}

Table 2. Travel times (in hours) between particular construction sites and a distribution center (marked as 0 ).

\begin{tabular}{ccccccc}
\hline & 0 & I & II & III & IV & V \\
\hline 0 & $\infty$ & 2 & 4 & 3 & 5 & 4 \\
I & 2 & $\infty$ & 2 & 6 & 4 & 4 \\
II & 4 & 2 & $\infty$ & 4 & 5 & 1 \\
III & 3 & 6 & 4 & $\infty$ & 5 & 2 \\
IV & 5 & 4 & 5 & 5 & $\infty$ & 6 \\
V & 4 & 4 & 1 & 2 & 6 & $\infty$ \\
\hline
\end{tabular}


Table 3. Results of survey conducted among civil engineers and managers

\begin{tabular}{ccccccc}
\hline \multirow{2}{*}{ Pearson } & \multicolumn{3}{c}{ Cost } & \multicolumn{4}{c}{ Delivery date } \\
\cline { 2 - 7 } & $a_{1}$ & $m_{1}$ & $c_{1}$ & $a_{2}$ & $m_{2}$ & $c_{2}$ \\
\hline 1 & 4 & 6 & 7 & 4 & 6 & 8 \\
2 & 5 & 8 & 10 & 6 & 7 & 8 \\
3 & 5 & 9 & 10 & 5 & 9 & 10 \\
4 & 3 & 5 & 7 & 3 & 5 & 7 \\
5 & 6 & 8 & 9 & 4 & 6 & 7 \\
6 & 7 & 8 & 9 & 2 & 4 & 5 \\
7 & 7 & 10 & 10 & 3 & 4 & 5 \\
8 & 5 & 6 & 9 & 4 & 7 & 8 \\
9 & 5 & 7 & 8 & 5 & 8 & 9 \\
10 & 8 & 9 & 10 & 1 & 3 & 6 \\
11 & 4 & 5 & 8 & 6 & 8 & 9 \\
\hline Standardized & 0,398649 & 0,547297 & 0,655405 & 0,290541 & 0,452703 & 0,554054 \\
weights & & $v_{1}=0,533784$ & & & $v_{2}=0,432432$ & \\
\hline Defuzzified & & &
\end{tabular}

The example was solved in the Microsoft Excel 2007 Program with the use of Solver add-in.

The following solution was received:

- a car route A covers the following points: 0-III-I-0 (or 0-I-III-0),

- a car route B covers the following points: 0-II-V-0 (or 0-V-II-0).

For the achieved solution, the degree of operating time of a car A driver is 11 hours (including one hour at the increased wage rate) when the car is used up to $100 \%$, whereas the operating time of a car B driver is 9 hours (including one hour at the increased wage rate) when the car is used up to $42 \%$. The timeliness coefficient of supplies is $50 \%$ construction $\mathrm{V}$ was served on the day in question, whereas the material to the construction IV will be delivered on the next day.

\section{Conclusion}

Small and medium construction enterprises have the barriers, characteristic for their sector, limiting their development which enforce application of strategies adapted to the needs of MSP [3, 6]. One of the concepts allowing the acceptance of advantages and possibilities of small and medium enterprises is the cluster supply chain. Such a concept allows overcoming some of the problems characteristic of MSP. Owing to the application of cluster supply chain, small and medium construction businesses can eliminate the problem of economies of scale and successfully compete with large construction companies operating on the market $[3,6]$.

A multi-criteria mathematical model of milk runs problem, presented in this work, with regard to the criteria of costs and timeliness, can be implemented in the case of distribution centers functioning as part of cluster supply chain. The application of a 
developed model can increase the degree of capacity use, as well as the driver's operating time, simultaneously decreasing unit costs of material distribution.

\section{Acknowledgments}

This work was financially supported by Ministry of Science and Higher Education within the statutory research number S/63/2015.

\section{References}

1 Gołembska E. Kompedium wiedzy o logistyce. Wydawnictwo Naukowe PWN, Warszawa 2004.

2 Sobotka A. Logistka przedsiębiorstw i przedsięwzięć budowlanych. Wydawnictwa AGH, Kraków 2010.

3 Tomczak M. Model decyzyjny dostaw realizowanych przez centrum dystrybucyjne dla potrzeb matych i średnich przedsiębiorstw budowlanych. Logistyka (2014) 6358-6366.

4 Marler R.T., Arora J.S. Survey of multi-objective optimization methods for engineering. Structural and Multidisciplinary Optimization 26 (2004) 369-395.

5 Biruk S., Jaśkowski P., Sobotka A. Zarządzanie w budownictwie, Organizacje, procesy, metody. Wydawnictwo Politechniki Lubelskiej, Lublin 2003.

6 Tomczak M. Problemy $w$ logistyce małych $i$ średnich przedsiębiorstw budowlanych. TTS Technika Transportu Szynowego 10 (2013) 637-645.

7 Saad M., Jones M., James P. A review of the progress towards the adoption of supply chain management (SCM) relationships in construction. European Journal of Purchasing \& Supply Management 8 (2002) 173-183.

8 Meehan J., Muir L. SCM in Merseyside SMEs: benefits and barriers. The TQM Journal 20 (2008) 223-232.

9 Porter M.E. Porter o konkurencji. Polskie Wydawnictwo Ekonomiczne, Warszawa 2001.

10 Quayle M. A study of supply chain management practice in UK industrial SMEs. Supply Chain Management: An International Journal 8 (2003) 79-86.

11 Robbins S.P. Zachowania $w$ organizacji. Polskie Wydawnictwo Ekonomiczne, Warszawa 2004.

12 Chen H., Themistocleous M., Chiu K.H. Approaches to supply chain integration followed by SMEs: An exploratory case study. The $10^{\text {th }}$ Americas conference on information systems, New York 2004.

13 Xue X., Wei Z., Zeng Z. The design of service system for SMEs collaborative alliance: Cluster Supply Chain. Journal of Software 6 (2011) 2146-2153.

14 Xue X., Wei Z., Zeng Z. Framework of analysis service-centric cluster supply chain: a case study of collaborative procurement. Journal of Software 7 (2012) 733-740.

15 Trzaskalik T. Wielokryterialne wspomaganie decyzji, Metody izastosowania. Polskie Wydawnictwo Ekonomiczne, Warszawa 2014.

16 Tzeng G. H., Huang J. J. Multiple attribute decision making, methods and applications. CRC Press, London 2011.

17 Yan S., Lai W. An optimal scheduling model for ready mixed concrete supply with overtime considerations. Automation in Construction 6 (2007) 734-744. 
